\title{
Readiness of Sudanese Pharmacists to Counsel Patients about Medical Devices
}

\author{
Ahmed Ibrahim Fathelrahman \\ Department of Clinical Pharmacy, College of Pharmacy, Taif University, Saudi Arabia \\ Received September 20, 2020; Revised October 26, 2020; Accepted November 29, 2020
}

\section{Cite This Paper in the following Citation Styles}

(a): [1] Ahmed Ibrahim Fathelrahman, "Readiness of Sudanese Pharmacists to Counsel Patients about Medical Devices," Advances in Pharmacology and Pharmacy, Vol. 8, No. 4, pp. 59 - 65, 2020. DOI: 10.13189/app.2020.080401.

(b): Ahmed Ibrahim Fathelrahman (2020). Readiness of Sudanese Pharmacists to Counsel Patients about Medical Devices. Advances in Pharmacology and Pharmacy, 8(4), 59 - 65. DOI: 10.13189/app.2020.080401.

Copyright $\odot 2020$ by authors, all rights reserved. Authors agree that this article remains permanently open access under the terms of the Creative Commons Attribution License 4.0 International License

\begin{abstract}
The general aim of the present study was to assess the readiness of pharmacists from a low-income country to counsel patients about medical devices. This cross-sectional study was conducted among Sudanese pharmacists using a convenience sampling technique. An online survey was used to collect data using Google forms. The survey link was distributed to pharmacists using social media. The main outcomes were awareness, sources of information, self-rating of ability to use, and self-rating of confidence to counsel patients about medical devices. In total, 130 pharmacists responded to the online survey. Most respondents were aged 25-54 years (87.8\%), and the proportion of males $(53.8 \%)$ was slightly higher. Overall, the study revealed an acceptable level of preparedness to counsel patients about medical devices with better preparedness for some devices and less preparedness concerning others such as respirometers and implanted devices. Thermometers, weighing scales, syringes, and blood glucose and blood pressure monitors were reported as the most commonly used devices by pharmacists for their own treatment and were top-ranked in terms of their ability to be used and in terms of confidence to counsel patients. In conclusion, the Sudanese pharmacists surveyed in this study reported an acceptable readiness to counsel patients on medical devices. Overseas, board-certified pharmacists and those who received clinical training showed significantly better preparedness than other respondents.
\end{abstract}

Keywords Medical Devices, Pharmacists, Sudanese Population, Readiness, Counseling Practices, Low- and Middle-income Countries

\section{Introduction}

Patients seldom use medical devices properly - even the ones commonly used or considered simple [1-3]. In a study conducted in Saudi Arabia, about half of the mothers were unable to measure an accurate dose of paracetamol using oral dosing syringes, droppers, or dosing cups; and more than two-thirds had not had previous counseling on the proper use of liquid-medication measuring devices [4], which can also be extrapolated to more sophisticated medical devices. This issue demands attention of healthcare professionals, specially pharmacists in low- and middle-income countries. These professionals could then counsel and train the general public on how to use medical devices.

Nevertheless, some studies suggest that most health care professionals are also inexperienced in using simple devices [5]. If simple, commonly used devices such as inhalers are subjected to high rates of errors and mistakes during use, we can infer that the problem could be much more serious regarding more sophisticated devices. This highlights the urgent need to assess healthcare professionals' awareness and their ability to use and counsel patients about medical devices, particularly in lowand middle-income countries.

\section{Study Problem}

To our knowledge, no studies have been conducted to evaluate the readiness of pharmacists to counsel patients 
regarding medical devices in Sudan and Africa, in general. Collecting such information will help improve pharmacists' contribution to this underserved area of practice.

\section{Study Goal and Questions}

The aim of the present study was to assess Sudanese pharmacists' readiness to counsel patients about medical devices. Specifically, the study aimed to answer five research questions: a) which medical devices do the respondents come across during practice? b) which medical devices are used by the respondents to treat personal illnesses? c) how frequently do respondents consult certain sources of information about medical devices? d) to what extent do the respondents know how to use common medical devices? and e) to what extent are the respondents confident about counseling patients regarding those devices?

\section{Hypothesis}

We hypothesized that pharmacists' awareness about and their experiences with medical devices in general are not high. However, pharmacists would be ready to counsel patients about medical devices they are familiar with, either by observing the devices being used or using them themselves. We believe that a pharmacist who knows how to use medical devices is interested in counseling patients about such devices.

\section{Methodology}

\section{Study Design and Participants}

This was a cross-sectional descriptive study conducted from February to June 2020. The subjects were Sudanese pharmacists that were chosen using a convenience sampling technique.

\section{Data Collection}

An online survey (Google forms) was used to collect data. The survey link was made available to pharmacists using social media. The link was sent primarily to pharmacists via professional WhatsApp groups; some key pharmacists were asked to distribute links in other professional groups, including on Facebook. Reminders were frequently sent in those groups to encourage participation in the survey.

\section{Sample Size}

There is no updated published statistics on the number of actively employed Sudanese pharmacists. To our knowledge, the only available records were from 2009 , and it revealed 4710 active pharmacists in Sudan [6]. If actively employed Sudanese pharmacists were at least 5,000 people, we planned to recruit a sample of 400 to 500 pharmacists to represent the population of pharmacists (approximately $10 \%$ ). However, using the software "PS Power and Sample Size Program," we verified that $<64$ participants per group was enough to detect a significant difference between two groups (i.e. total 128) using Student's t-test with a power of $0.8, \alpha$ (i.e. significance level) $=0.05, \sigma$ (sigma: within group standard deviation) $=0.6$, and $\delta$ (delta: a difference in population mean) $=0.3$.

\section{The Survey}

The original survey included 11 sections; however, this paper reports only six, as follows: demographic background information, types of medical devices respondents encountered during practice, medical devices used personally by the respondents during practice, how frequently the respondents used certain sources for information on medical devices (5-point Likert scale), self-rating of their ability to use or operate medical devices (5-point Likert scale), and self-rating of their confidence to counsel patients regarding medical devices (5-point Likert scale).

\section{Validation of Questionnaire}

The questionnaire items have been validated for the face and content via feedback from four academic staff who have good experience with teaching and research in the areas of pharmacy practice and healthcare services working alongside a clinician.

\section{Statistical Analysis and Data Presentation}

Data were analyzed and presented descriptively and comparatively using SPSS. Average scores on pharmacists' self-ratings on the ability to use medical devices and confidence to counsel patients regarding these devices were computed. Comparisons between groups concerning sex, residence (overseas vs. inside Sudan), board certification, and clinical training were conducted using Student's t-test. One-way analysis of variance was used to test differences between groups concerning age, sector, years of experience, work location (rural, suburban, and urban), and highest qualifications. Results with a p-value of $<0.05$ were considered statistically significant.

\section{Results}

\section{Demographic Characteristics}

One hundred and thirty pharmacists responded to the online survey. Most respondents were aged 25-54 years $(87.8 \%)$, and the proportion of males $(53.8 \%)$ was slightly 
higher (Table 1). Respondents with master's degree (62.3\%) represented the highest proportion, followed by those with bachelor's degree (23.1\%). About two-thirds of pharmacists $(65.4 \%)$ were based in Sudan. By sector, most respondents worked in academia $(30.8 \%)$, followed by those in community pharmacies $(25.4 \%)$ and hospital pharmacies (14.6\%). Most respondents received clinical training $(70 \%)$, and about one-third of them received board certification $(30 \%)$.

Table 1. Demographic and background information of respondents $(\mathrm{n}=$ 130)

\begin{tabular}{|c|c|c|}
\hline Variable & Categories & $\begin{array}{l}\text { Frequency } \\
(\%)\end{array}$ \\
\hline \multirow{6}{*}{ Age (years) } & $<25$ & $2(1.5)$ \\
\hline & $25-34$ & $37(28.5)$ \\
\hline & $35-44$ & $43(33.1)$ \\
\hline & $45-54$ & $34(26.2)$ \\
\hline & $55-65$ & $10(7.7)$ \\
\hline & $>65$ & $4(3.1)$ \\
\hline \multirow{2}{*}{ Sex } & Male & $70(53.8)$ \\
\hline & Female & $60(46.2)$ \\
\hline \multirow{2}{*}{ Residence } & Inside Sudan & $85(65.4)$ \\
\hline & Overseas & 45 (34.6) \\
\hline \multirow{4}{*}{$\begin{array}{l}\text { Highest } \\
\text { qualification }\end{array}$} & Bachelor's & $30(23.1)$ \\
\hline & Master's & $81(62.3)$ \\
\hline & PharmD & $3(2.3)$ \\
\hline & $\mathrm{PhD}$ & $16(12.3)$ \\
\hline \multirow{9}{*}{$\begin{array}{l}\text { Sector representing } \\
\text { main } \quad \text { current } \\
\text { professional career }\end{array}$} & Academia & $40(30.8)$ \\
\hline & Community pharmacy & $33(25.4)$ \\
\hline & Hospital pharmacy & $19(14.6)$ \\
\hline & Regulation affairs & $14(10.8)$ \\
\hline & Insurance sector & $7(5.4)$ \\
\hline & $\begin{array}{l}\text { Drug marketing (medical } \\
\text { representative) }\end{array}$ & $7(5.4)$ \\
\hline & $\begin{array}{l}\text { Manufacturing } \\
\text { production and quality } \\
\text { control) }\end{array}$ & $5(3.8)$ \\
\hline & Research institution & $3(2.3)$ \\
\hline & $\begin{array}{l}\text { Non-governmental } \\
\text { organization }\end{array}$ & $2(1.5)$ \\
\hline \multirow{2}{*}{$\begin{array}{l}\text { Extra qualifications } \\
\text { and experiences* }\end{array}$} & Holds board certification & $39(30)$ \\
\hline & Received clinical training & $91(70)$ \\
\hline
\end{tabular}

* Categories are not mutually exclusive.

\section{Awareness about Medical Devices}

Pharmacists' awareness regarding medical devices was attributed to observing someone using the device during practice (Table 2) or using the devices themselves (Table 3). The in-use medical devices that were observed in the highest proportion by the respondents were related to pulmonary $(83.8 \%)$, followed by those related to cardiology and endocrinology (64.6\% each). Syringes $(83.1 \%)$, weighing scales $(79.2 \%)$, thermometers $(79.2 \%)$, blood pressure monitors $(73.1 \%)$, first-aid equipment $(68.5 \%)$, and blood glucose monitors $(65.4 \%)$ were the most commonly used devices by pharmacists. Implanted devices $(2.3 \%)$ were the least used, followed by respirometers $(18.5 \%)$.

Table 2. Types of medical devices (by therapeutic category) encountered by respondents during practice

\begin{tabular}{lc}
\hline Devices related to & $\begin{array}{c}\text { Frequency } \\
(\boldsymbol{\%})\end{array}$ \\
\hline Endocrinology & $84(64.6)$ \\
Cardiology & $84(64.6)$ \\
Pulmonary & $109(83.8)$ \\
Gastroenterology & $34(26.2)$ \\
Nephrology & $35(26.9)$ \\
Urology & $51(39.2)$ \\
Oncology & $17(13.1)$ \\
Surgery & $56(43.1)$ \\
Orthopedics & $74(56.9)$ \\
Neurology & $30(23.1)$ \\
Psychiatry & $7(5.4)$ \\
Ophthalmology & $51(39.2)$ \\
\hline
\end{tabular}

Table 3. Medical devices used personally by respondent during practice

\begin{tabular}{lc}
\hline Devices & Frequency (\%) \\
\hline Puffers & $26(20)$ \\
Spacers & $41(31.5)$ \\
Dry powder inhalers & $54(41.5)$ \\
Nebulizers & $55(42.3)$ \\
Accuhalers & $23(17.7)$ \\
Turbuhalers & $38(29.2)$ \\
Blood pressure monitors & $95(73.1)$ \\
Heart rate monitors & $36(27.7)$ \\
Blood glucose monitors & $85(65.4)$ \\
Insulin pens & $48(36.9)$ \\
Pens other than insulin pens & $19(14.6)$ \\
Implanted devices & $3(2.3)$ \\
Weighing scales & $103(79.2)$ \\
Syringes & $108(83.1)$ \\
Stethoscope & $44(33.8)$ \\
Thermometers & $103(79.2)$ \\
Testing kits & $57(43.8)$ \\
First-aid equipment & $89(68.5)$ \\
Meters & $74(56.9)$ \\
Respirometers & $24(18.5)$ \\
\hline
\end{tabular}

Sources of Information about Medical Devices

Table 4 shows sources of information about medical devices commonly used by pharmacists. Overall, pharmaceutical companies' information enclosed with the device package was the most important source of information for the pharmacists (average score $=3.97$ ). The second most important source was pharmaceutical companies' promotional materials (average score $=3.13$ ). 
Table 4. Sources of information regarding medical devices among pharmacists

\begin{tabular}{lc}
\hline $\begin{array}{l}\text { Question: How frequently do you use the } \\
\text { following sources for information on medical } \\
\text { devices? }\end{array}$ & $\begin{array}{c}\text { Score } \\
\text { Mean } \\
\text { (standard } \\
\text { deviation) }\end{array}$ \\
\hline $\begin{array}{l}\text { Pharmaceutical companies' information } \\
\text { enclosed with devices package }\end{array}$ & $3.97(1.1)$ \\
$\begin{array}{l}\text { Pharmaceutical companies' promotional } \\
\text { materials (e.g., booklets, posters, and brochures) }\end{array}$ & $3.13(1.2)$ \\
$\begin{array}{l}\text { Pharmaceutical companies' representatives } \\
\text { Pharmaceutical companies' official websites }\end{array}$ & $2.66(1.1)$ \\
$\begin{array}{l}\text { Patient-oriented non-commercial websites } \\
\text { Regulatory authorities' official websites }\end{array}$ & $2.58(1.2)$ \\
$\begin{array}{l}\text { Pharmacy colleagues (others than company } \\
\text { representatives) }\end{array}$ & $2.41(1.4)$ \\
Medical doctors $2.69(1.2)$ \\
Workshops or conferences & $2.18(1.1)$ \\
Mobile applications & $2.39(1.1)$ \\
Professional textbooks and reference books & $2.6(1.3)$ \\
\hline
\end{tabular}

Pharmacists' Self-rating of Ability to Use or Operate Medical Devices

The 20 items cited on the question about the ability to use medical devices showed high reliability (Cronbach's alpha $=0.887$ ). Table 5 shows pharmacists' self-rating on the ability to use or operate medical devices on a five-point Likert scale. Five devices were highly rated with an average score of $>4$ : thermometers, weighing scales, syringes, blood glucose monitors, and blood pressure monitors.

Table 5. Pharmacists' self-rating on the ability to use or operate medical devices on a five-point Likert scale

\begin{tabular}{lc}
\hline $\begin{array}{l}\text { Question: To what extent do you know } \\
\text { how to use or operate the following } \\
\text { devices appropriately? }\end{array}$ & $\begin{array}{c}\text { Score } \\
\text { Mean (standard } \\
\text { deviation) }\end{array}$ \\
\hline Puffers & $2.89(1.3)$ \\
Spacers & $3.44(1.2)$ \\
Dry powder inhalers & $3.83(1.1)$ \\
Nebulizers & $3.82(1.1)$ \\
Accuhalers & $3.05(1.3)$ \\
Turbuhalers & $3.17(1.3)$ \\
Blood pressure monitors & $4.09(0.9)$ \\
Heart rate monitors & $2.69(1.3)$ \\
Blood glucose monitors & $4.07(1.1)$ \\
Insulin pens & $3.55(1.2)$ \\
Pens other than insulin pens & $2.65(1.4)$ \\
Implanted devices & $1.82(1.0)$ \\
Weighing scales & $4.07(1.2)$ \\
Syringes & $4.12(1.1)$ \\
Stethoscope & $2.68(1.3)$ \\
Thermometers & $4.27(0.9)$ \\
Testing kits & $3.12(1.3)$ \\
First-aid equipment & $3.58(1.2)$ \\
Meters & $3.57(1.3)$ \\
Respirometers & $2.25(1.1)$ \\
Overall score & $3.34(0.7)$ \\
\hline
\end{tabular}

Pharmacists' self-rating on the confidence to counsel patients about medical devices:

The 20 items cited on the question about the pharmacists' confidence to counsel patients about medical devices showed high reliability (Cronbach's alpha $=0.921)$. Table 6 shows the pharmacists' self-rating on their confidence to counsel patients about medical devices on a five-point Likert scale. The same top five devices rated highest in terms of ability to be used were ranked top in terms of confidence to counsel patients. All the five devices got scores $>4$ except for weighing scales, which got a slightly lower score (i.e., score $=3.97$ ).

Table 6. Pharmacists' self-rating on their confidence to counsel patients regarding medical devices on a five-point Likert scale

\begin{tabular}{|c|c|}
\hline $\begin{array}{l}\text { Question: To what extent are you } \\
\text { confident to counsel patients regarding } \\
\text { the following devices? }\end{array}$ & $\begin{array}{c}\text { Score } \\
\text { Mean (SD) }\end{array}$ \\
\hline Puffers & $2.78(1.4)$ \\
\hline Spacers & $3.48(1.2)$ \\
\hline Dry powder inhalers & $3.78(1.1)$ \\
\hline Nebulizers & $3.75(1.1)$ \\
\hline Accuhalers & $3.18(1.3)$ \\
\hline Turbuhalers & $3.35(1.3)$ \\
\hline Blood pressure monitors & $4.08(0.9)$ \\
\hline Heart rate monitors & $3.01(1.3)$ \\
\hline Blood glucose monitors & $4.10(0.9)$ \\
\hline Insulin pens & $3.55(1.2)$ \\
\hline Pens other than insulin pens & $2.88(1.3)$ \\
\hline Implanted devices & $2.14(1.2)$ \\
\hline Weighing scales & $3.97(1.2)$ \\
\hline Syringes & $4.09(1.1)$ \\
\hline Stethoscope & $2.72(1.4)$ \\
\hline Thermometers & $4.07(1.1)$ \\
\hline Testing kits & $3.07(1.3)$ \\
\hline First-aid equipment & $3.57(1.2)$ \\
\hline Meters & $3.46(1.3)$ \\
\hline Respirometers & $2.34(1.2)$ \\
\hline Overall score & $3.37(0.8)$ \\
\hline
\end{tabular}

Comparisons between Groups

There were no significant differences in the overall average scores by gender, sector, age group, years of experience, work location, or highest qualifications on the pharmacists' self-rating of ability to use/operate medical devices, and pharmacists' self-rating of confidence in counseling patients about medical devices. However, overseas pharmacists and those who were board-certified reported significantly higher ability to use or operate medical devices ( $p=0.037$ and 0.013 , respectively) and a higher rating on the confidence to counsel patients about medical devices ( $p=0.008$ and 0.025 , respectively) than their counterparts (Table 7). Those who received clinical training reported a significantly higher ability to use or operate medical devices than the pharmacists who were not trained $(\mathrm{p}=0.010)$. 
Table 7. Differences based on residence, board certification, and clinical training regarding the pharmacists' self-rating on the ability to use or operate medical devices and their self-rating on the confidence to counsel patients regarding medical devices

\begin{tabular}{|c|c|c|c|c|}
\hline Items & & & $\begin{array}{c}\text { Score } \\
\text { Mean (standard } \\
\text { deviation) }\end{array}$ & p-value \\
\hline \multirow[t]{6}{*}{$\begin{array}{l}\text { Pharmacists' self-rating on the ability to use or } \\
\text { operate medical devices on a five-point Likert scale }\end{array}$} & Residence & Inside Sudan $(\mathrm{n}=85)$ & $3.2(0.63)$ & 0.037 \\
\hline & & Overseas $(n=45)$ & $3.5(0.71)$ & \\
\hline & $\begin{array}{c}\text { Board } \\
\text { certification }\end{array}$ & Yes $(n=39)$ & $3.5(0.71)$ & 0.013 \\
\hline & & No $(n=91)$ & $3.2(0.63)$ & \\
\hline & Clinical training & Yes $(n=91)$ & $3.4(0.65)$ & 0.010 \\
\hline & & No $(n=39)$ & $3.1(0.66)$ & \\
\hline \multirow[t]{6}{*}{$\begin{array}{c}\text { Pharmacists' self-rating on the confidence to counsel } \\
\text { patients regarding medical devices on a five-point } \\
\text { Likert scale }\end{array}$} & Residence & Inside Sudan $(\mathrm{n}=85)$ & $3.2(0.73)$ & 0.008 \\
\hline & & Overseas $(n=45)$ & $3.6(0.77)$ & \\
\hline & $\begin{array}{c}\text { Board } \\
\text { certification }\end{array}$ & Yes $(n=39)$ & $3.6(0.79)$ & 0.025 \\
\hline & & No $(n=91)$ & $3.3(0.73)$ & \\
\hline & Clinical training & Yes $(\mathrm{n}=91)$ & $3.4(0.73)$ & 0.492 \\
\hline & & No $(\mathrm{n}=39)$ & $3.3(0.84)$ & \\
\hline
\end{tabular}

\section{Discussion}

The current study assessed the awareness and readiness of Sudanese pharmacists to counsel patients about medical devices based on self-reporting and not on their actual counseling practice. Despite the inclusion of pharmacists who differed by sector and place of residence, between-group similarities were more than just variability; it reflected a consistent trend of general readiness to counsel patients about medical devices.

In Sudan, most pharmacists practice in more than one sector (e.g., working in academia and taking night shifts in a community pharmacy or working as part-time staff in industry). However, in this study, we asked respondents to select the sector representing their main income. During the last 20 years, there has been a growing interest among Sudanese pharmacists in clinical pharmacy training and postgraduate qualifications because of the competition for jobs, particularly in central Sudan $[7,8]$. This explains the rate of master's holders $(62.3 \%)$ and the clinical pharmacy training received by most respondents (70\%). In addition, about one-third of respondents held board certifications.

In this context, the study revealed an acceptable level of readiness to counsel patients about medical devices with better preparedness concerning some devices and less preparedness concerning others. Pharmacists located outside Sudan have shown better preparedness for counseling about medical devices. Most of the overseas pharmacists in this study were located in Gulf countries (73.3\% of overseas); their better preparedness reflects a higher availability of devices in Gulf countries compared with Sudan. However, government policies and regulations and the characteristics of pharmacy practice in Gulf countries and Sudan are comparable [9].

The pharmacists in this study relied more on pharmaceutical companies' enclosed information and promotional materials to know about medical devices. Pharmaceutical companies are a primary source of information on medications for practicing pharmacists in many countries, particularly in low- and middle-income countries. In Jordan, the Monthly Index of Medical Specialties, which is based on pharmaceutical companies' information, was a primary source of medicine information for pharmacists, followed by pharmaceutical companies' representatives [10]. Improving access to reliable and accurate information based on manufacturers and regulatory bodies supports the practice of pharmacists and other healthcare professionals concerning medical devices. Fathelrahman [11] recommends establishing information-sharing systems using resources of different institutions in low- and middle-income countries; it would overcome the scarcity of medicine information and reduce issues of access or quality. For example, health information centers could build online databases based on industry and regulator facilities and conduct regular training for practicing pharmacists. These changes would improve the pharmacists' knowledge and experience on medical devices. Peterson-Clark et al [12] assessed the Australian pharmacists' online information literacy and concluded that "pharmacists' opinion about and skills in using the internet are generally low and are extremely varied" and that "pharmacists need to develop their skills in finding and interpreting online information in a structured, time-efficient manner, for their own professional development and for their consumers."

In the present study, pharmacists included thermometers, 
weighing scales, syringes, blood glucose monitors, and blood pressure monitors as devices they were capable to use. These devices represent common items in the market that are widely used by pharmacists, other healthcare professionals, as well as patients. Moreover, these were almost the same five top-ranked devices that pharmacists use themselves; and they were also the five top-ranked items in terms of the respondents' confidence to counsel patients. These results indicate an association between the personal use of a device, perceived ability to use it, and confidence to counsel patients about it. Being exposed to medical devices early while studying pharmacy prepares future pharmacists for counseling during practice. Ratassepp et al. [13] found a connection between self-evaluated knowledge on counseling and the implementation of new extended community pharmacy services regarding personal medical devices and various drug-delivery product counseling services. The relationship between early exposure to a practical experience and confidence in counseling has been assessed on other topics. For example, experience with a syringe exchange program was perceived as helpful in improving pharmacy student's confidence in counseling patients on naloxone use [14]. This supports the notion of the experiential training role in pharmacy colleges to improve competence and confidence for a good practice upon graduation. Pharmacy colleges in low- and middle-income countries are advised to incorporate medical-device training in the introductory and advanced experiential learning and clinical skill labs. Continuing professional development (CPD) programs for practicing pharmacists in low- and middle-income countries should consider incorporating medical devices in training as pharmacy is a fast-growing area and pharmacists' involvement in it is still low.

Compared to their counterparts, pharmacists outside Sudan and those who are board-certified reported higher scores on the perceived ability to use medical devices as well as higher scores on confidence in counseling. Pharmacists who received clinical training reported higher scores on the perceived ability to use/operate medical devices. This may indicate that further qualifications, clinical training, and external (overseas) practice exposures improve awareness and confidence in counseling about medical devices.

\section{Study Limitations}

A limitation of the present study was the impossibility to achieve the required sample size according to the original study design. The study was conducted during the Corona virus (COVID-19) pandemic. Because of the difficult conditions created by the coronavirus outbreak, such as lockdown and other restrictions, a preliminary plan to hire experienced data collectors to collect data from community pharmacies was cancelled and it was decided to analyze only data collected online. These data showed an overall consistent trend of readiness to counsel patients about medical devices, with some differences between groups that were also consistent since they explain each other.

\section{Recommendations}

Due to the increased availability and use of medical devices, pharmacy colleges in low- and middle-income countries should consider incorporating medical-device training in programs' curricula. Professional associations should consider offering CPD courses in medical-device training. These courses could focus on knowing various categories and features of medical devices, training professionals on how to operate medical devices commonly used by patients, and how to educate and counsel patients on the correct use of medical devices.

\section{Conclusions}

The Sudanese pharmacists surveyed in this study reported an acceptable but variable readiness to counsel patients on medical devices. There were differences between pharmacists by residence, board certification, and clinical training in the overall scores on the ability and confidence to counsel patients. Devices commonly available in the market were perceived to be used better by pharmacists. Five devices, namely thermometers, weighing scales, syringes, and blood glucose and blood pressure monitors were among the devices reported to be most-used personally by pharmacists in their own practice and were top-ranked in terms of their ability to be used and in terms of confidence to counsel patients on their usage. The perceived ability to use a device is likely a reflection of the pharmacist's exposure to such devices, and it is likely to be related to the ability to counsel patients on how to use them.

\section{Acknowledgements}

The author would like to acknowledge the assistance of the following academicians, practitioners, and researchers in validating the questionnaire for the face and content: Professor Ab Fatah Ab Rahman (Professor of Clinical Pharmacy, Faculty of Medicine \& Health Sciences, Universiti Sultan Zainal Abidin, Malaysia), Professor Mohamed Izham Mohamed Ibrahim (Professor of Social \& Administrative Pharmacy, College of Pharmacy, Qatar University), Dr Ali Alshahrani (College of Pharmacy, Taif University, Saudi Arabia), Dr. Mona Alshiekh (College of Pharmacy, Taif University, Saudi Arabia), and Dr. Fathielrahman Ibrahim Fathielrahman, MD, Ophthalmology. 


\section{REFERENCES}

[1] Sanchis J et al. Systematic review of errors in inhaler use: has patient technique improved over time? Chest, 150, pp. 394-406, 2016.

[2] Usmani OS et al. Critical inhaler errors in asthma and COPD: a systematic review of impact on health outcomes. Respiratory Research, 19, pp. 10, 2018.

[3] Klijn SL et al. Effectiveness and success factors of educational inhaler technique interventions in asthma \& COPD patients: a systematic review. NPJ Primary Care Respiratory Medicine, 27, pp. 1-10, 2017.

[4] Almazrou S et al. Ability of Saudi mothers to appropriately and accurately use dosing devices to administer oral liquid medications to their children. Drug, Healthcare and Patient Safety, 7, pp. 1, 2015.

[5] Plaza V et al. Errors in the use of inhalers by health care professionals: a systematic review. The Journal of Allergy and Clinical Immunology: in Practice, 6, pp. 987-995, 2018.

[6] Alfadl AA, Ali GK, Yousif MA, Babekir MF. Pharmacy practice in Sudan. In Fathelrahman AI, Ibrahim MIM \& Wertheimer AI (editors), Pharmacy Practice in Developing Countries. Elsevier: Academic Press, 2016, pp. 319-341

[7] Mohamed SS. Current state of pharmacy education in the Sudan. American Journal of Pharmacy Education, 75, pp. 1, 2011.

[8] Elsadig $\mathrm{H}$ et al. Exploring the challenges for clinical pharmacists in Sudan. International Journal of Clinical Pharmacy, 39, pp. 1047-1054, 2017.

[9] Ibrahim MI, Fathelrahman AI, Wertheimer AI. Comparative analysis and conclusion. In Pharmacy Practice in Developing Countries. Elsevier: Academic Press, 2016, pp. 449-467.

[10] Wazaify $\mathrm{M}$ et al. Drug information resources at community pharmacies in Amman, Jordan. International Journal of Pharmacy Practice, 17, pp. 151-155, 2009.

[11] Fathelrahman AI. Issues on sources, access, extent, and quality of information available among pharmacists and pharmacy personnel to practice effectively. In Ibrahim MIM, Wertheimer AI \& Babar Z-U D (editors), Elsevier: Academic Press, 2018, pp. 363-383.

[12] Peterson - Clark G et al. Pharmacists' online information literacy: an assessment of their use of Internet - based medicines information. Health Information \& Libraries Journal, 27, pp. 208-216, 2010.

[13] Ratassepp T, Shagandina A, Turunen J, Ahonen R, Heinämäki J, Volmer D. Counseling in the use of personal medical devices and drug-delivery products - A traditional or extended community pharmacy service. Farmacia, 63, pp. 388-393, 2015.

[14] Kuryluk V et al. Naloxone counselling: Confidence and attitudes of student pharmacists after a volunteer syringe exchange experience. Currents in Pharmacy Teaching \& Learning, 12, pp. 429-433, 2020. 